\title{
Friction factors of power-law fluids in chevron-type plate heat exchangers
}

\author{
Carla S. Fernandes ${ }^{\mathrm{a}, *}$, Ricardo P. Dias ${ }^{\mathrm{b}, \mathrm{c}}$, João M. Nóbrega ${ }^{\mathrm{d}}$, João M. Maia ${ }^{\mathrm{d}}$ \\ a Departamento de Matemática, Escola Superior de Tecnologia e de Gestão, Instituto Politécnico de Bragança, Campus de Santa Apolónia, $5301-857$ Bragança, Portugal \\ ${ }^{\mathrm{b}}$ Departamento de Tecnologia Química e Biológica, Escola Superior de Tecnologia e de Gestão, Instituto Politécnico de Bragança, Campus de Santa Apolónia, \\ 5301-857 Bragança, Portugal \\ ${ }^{\mathrm{C}}$ CEFT - Centro de Estudos de Fenómenos de Transporte, Faculdade de Engenharia da Universidade do Porto, 4200-465 Porto, Portugal \\ ${ }^{\mathrm{d}}$ IPC - Institute for Polymers and Composites, Departamento de Engenharia de Polímeros, Universidade do Minho, 4800-058 Guimarães, Portugal
}

\section{A R T I C L E I N F O}

\section{Article history:}

Received 10 December 2007

Received in revised form 19 April 2008

Accepted 17 May 2008

Available online 25 May 2008

\section{Keywords:}

Plate heat exchangers

Power-law fluids

Generalised Reynolds number

Friction factor

Tortuosity

\begin{abstract}
A B S T R A C T
In the present work laminar flows of Newtonian and power-law fluids through cross-corrugated chevrontype plate heat exchangers (PHEs) are numerically studied in terms of the geometry of the channels. The plates area enlargement factor was a typical one (1.17), the corrugation angle, $\beta$, varied between $30^{\circ}$ and $60^{\circ}$ and the flow index behaviour, $n$, between 0.25 and 1 . Single friction curves $f R e_{g}=K$ for both Newtonian and non-Newtonian fluids are proposed for each $\beta$ by developing an adequate definition of the generalised Reynolds number, $R e_{\mathrm{g}}$. The coefficient $K$ compares well with experimental data, for all (seven) values of $\beta$, and depends on the tortuosity coefficient, $\tau$. It was found that, for each $\beta, \tau$ decreases with the decrease of $n$. Food fluids are frequently processed in PHEs and usually behave as non-Newtonian fluids. This study can be useful in engineering applications as well as in the characterization of transport phenomena in PHEs.
\end{abstract}

() 2008 Elsevier Ltd. All rights reserved.

\section{Introduction}

Food fluids are frequently processed in plate heat exchangers (PHEs) and usually behave as non-Newtonian fluids, this behaviour being scarcely considered for PHEs design purposes (Rene et al., 1991; Kim et al., 1999). Moreover, many food fluids (milk and milky desserts, fruit and vegetable juices, meat sauces, concentrates, etc.) processed in PHEs have a high viscosity and, therefore, data obtained in laminar flow regime is useful to practical applications (Rene et al., 1991; Metwally and Manglik, 2000, 2002; Leuliet et al., 1987, 1988).

The rheology of numerous food fluids (Steffe, 1996) can be described by a relation of the power-law type:

$\eta=\eta_{0} \dot{\gamma}^{n-1}$,

$\dot{\gamma}$ representing the shear rate, $\eta_{0}$ the consistency index, $n$ the flow index behaviour and $\eta$ the apparent viscosity.

The heat exchange to stirred yogurt $(n=0.42)$ in a short length chevron-type plate heat exchanger was numerically studied by Fernandes et al. (2005, 2006). The PHE had an area enlargement factor, $\phi$, close to 1.1 , a corrugation angle, $\beta$, of $30^{\circ}$ and an interplates distance (Fig. 1), $b$, of $2.6 \mathrm{~mm}$. A good agreement was found between the numerical thermal data (Fernandes et al., 2005, 2006;

\footnotetext{
* Corresponding author. Tel.: +351 273303 127; fax: +351 273313051 .

E-mail address: cveiga@ipb.pt (C.S. Fernandes).
}

Maia et al., 2007) and the experimental data from Afonso et al. (2003) for stirred yoghurt.

The thermal correlations - including important entry effects developed by Fernandes et al. (2006) were based on apparent viscosity. The thermal or hydraulic correlations including apparent viscosity are of limited utility since this viscosity is difficult to predict, due to the geometrical complexity of the PHEs passages and, therefore, due to the complex behaviour of the shear rate.

One way of solving the referred limitation is to use a generalised viscosity. From the works of Metzner and Reed (1955) and Kozicki et al. (1966) it follows that the generalised viscosity, $\eta_{\mathrm{g}}$, for the flow of power-law fluids in ducts of arbitrary cross-section can be defined as (Delplace and Leuliet, 1995; Gut and Pinto, 2003; Carezzato et al., 2007):

$\eta_{\mathrm{g}}=\eta_{0}\left(\frac{K}{2}\right)^{n-1}\left(\frac{u}{D_{\mathrm{H}}}\right)^{n-1} g^{n}(n)$,

where $u$ is the mean velocity, $D_{\mathrm{H}}$ the hydraulic diameter, $g(n)$ a hyperbolic function of $n$ and $K$ a geometrical parameter given by the product of the Fanning friction factor, $f$, and the Reynolds number, $R e_{\mathrm{g}}$, for a Newtonian fluid under laminar flow conditions (Metzner and Reed, 1955; Delplace and Leuliet, 1995):

$f R e_{\mathrm{g}}=K$.

$R e_{\mathrm{g}}$ can be calculated by:

$R e_{\mathrm{g}}=\frac{\rho u D_{\mathrm{H}}}{\eta_{\mathrm{g}}}$, 


\section{Nomenclature}

a geometrical parameter (-)

c geometrical parameter (-)

$K \quad$ coefficient of $f R e_{\mathrm{g}}$ expression (-)

$K_{0} \quad$ shape factor (-)

$B \quad$ inter-plates distance $(\mathrm{m})$

$D_{\mathrm{H}} \quad$ hydraulic diameter $(\mathrm{m})$

$f \quad$ Fanning friction factor $(-)$

$g(n) \quad$ hyperbolic function of $n(-)$

$L \quad$ plate length ( $\mathrm{m}$ )

$M_{\mathrm{v}} \quad$ volumetric flow rate $\left(\mathrm{m}^{3} \mathrm{~s}^{-1}\right)$

$n \quad$ flow index behaviour $(-)$

$p_{\mathrm{x}} \quad$ corrugation pitch on the main flow direction $(\mathrm{m})$

$R e_{\mathrm{g}} \quad$ generalised Reynolds number (-)

$u$ mean velocity $\left(\mathrm{m} \mathrm{s}^{-1}\right)$

$u_{\mathrm{i}} \quad$ average interstitial velocity $\left(\mathrm{ms}^{-1}\right)$

$w \quad$ width of the channel (m) $\begin{array}{ll}x, y, z & \text { cartesian coordinates }(\mathrm{m}) \\ x^{*} & \text { normalized length }(-)\end{array}$

Greek symbols

$\alpha \quad$ geometrical parameter (-)

$\beta \quad$ corrugation angle $\left(^{\circ}\right)$

$\Delta P \quad$ pressure drop $(\mathrm{Pa})$

$\phi \quad$ area enlargement factor (-)

$\gamma \quad$ channel aspect ratio on the main flow direction $(-)$

$\dot{\gamma} \quad$ shear rate $\left(\mathrm{s}^{-1}\right)$

$\eta \quad$ apparent fluid viscosity (Pas)

$\eta_{\mathrm{g}} \quad$ generalised fluid viscosity (Pas)

$\eta_{0} \quad$ consistency index $\left(\mathrm{Pas}^{n}\right)$

$\rho \quad$ fluid density $\left(\mathrm{kg} \mathrm{m}^{-3}\right)$

$\tau \quad$ tortuosity (-) where $\rho$ is the fluid density and $D_{\mathrm{H}}$ the hydraulic diameter:

$D_{\mathrm{H}}=\frac{4 \times \text { channel flow area }}{\text { wetted surface }} \cong \frac{2 b}{\phi}$.

The mean velocity, $u$, is given by:

$u=\frac{M_{\mathrm{v}}}{w b}$,

where $M_{\mathrm{v}}$ is the volumetric flow rate and $w$ the channel width.

The Fanning friction factor can be estimated by:

$f=\frac{\Delta P D_{\mathrm{H}}}{2 L \rho u^{2}}$,

with $\Delta P$ the pressure drop and $L$ the length of the channel.

Kozicki et al. (1966) studied the flow of power-law fluids in straight ducts of arbitrary but uniform cross-section area along the flow direction and proposed the following relation for $g(n)$ :

$g(n)=a \frac{1}{n}+c$,

$a$ and $c$ being geometrical parameters of the duct. For the same type of ducts, Delplace and Leuliet (1995) related $a$ and $c$ with $K$, reducing to one the number of geometrical parameters involved in Eq. (2).

PHE passages containing cross-corrugated chevron-type plates are much more complex than the ducts studied by Kozicki et al. (1966) due to the presence of a series of expansions and contractions (Edwards et al., 1974). As a result of this complexity, Edwards

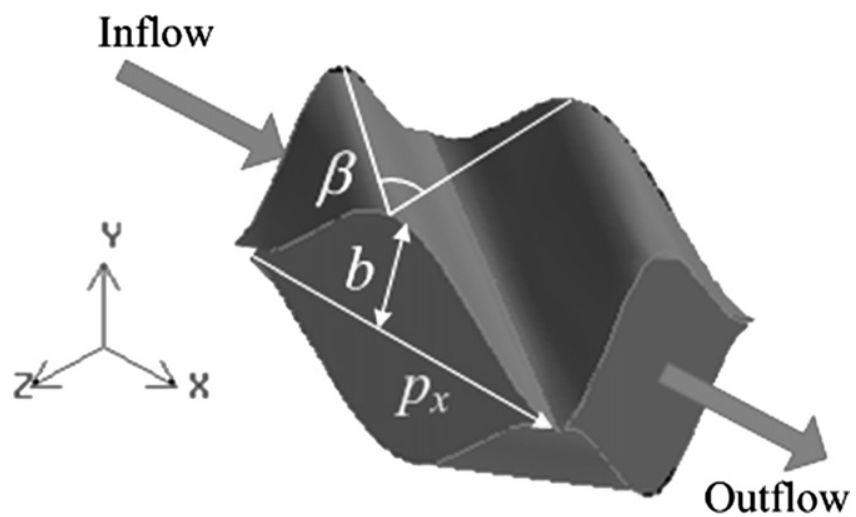

Fig. 1. Unitary cell for $\beta=55^{\circ}$. et al. (1974) and Charre et al. (2002) analysed the performance of chevron-type PHEs making use of the theory developed for granular beds (Broniarz-Press et al., 2007; Chhabra et al., 2001; Dias et al., 2006, 2007, 2008).

Delplace and Leuliet (1995) explored the applicability of Eq. (8) to the area of PHEs but suggested that due to the complexity of the passages of these equipments the best way of defining a hyperbolic function $g(n)$ is to measure the pressure drop and flow rates under laminar isothermal conditions with different shear-thinning fluids, i.e., different values of $n$, as it was performed in previous works (Rene et al., 1991). As a result of this empirical methodology, Rene et al. (1991) proposed the following expression for $g(n)$ :

$g(n)=\left(\frac{2}{3}+\frac{1 / 3}{n}\right)\left(\frac{1}{n}\right)^{\alpha / n}$

In Eq. (9) the geometrical parameter $\alpha$ assumed a value of 0.3 and 0.1 for PHEs containing chevron-type plates with $\beta=30^{\circ}$ and a washboard plates, respectively (Rene et al., 1991). Eq. (9) allowed establishing, for each PHE, a single friction curve equation (Eq. (3)) for both Newtonian and shear-thinning fluids (Delplace and Leuliet, 1995; Rene et al., 1991). It is important to note that this methodology, developed under isothermal conditions, can be used successfully in non-isothermal situations (Delplace and Leuliet, 1995; Leuliet et al., 1987, 1988).

Fernandes et al. (2007) studied the relation between the geometrical properties of the chevron-type PHEs plates and the coefficient $K$, for Newtonian flows under laminar regime and developed the relation:

$K=(\underbrace{1+0.5 \sqrt{\left(\frac{1}{\sin (\beta)}\right)^{\gamma}-1}}_{\tau})^{2} \times \underbrace{16\left(\frac{90}{\beta}\right)^{0.6554-0.0929 \gamma}}_{K_{0}}$,

$\gamma$ being the channel aspect ratio in the main flow direction:

$\gamma=\frac{2 b}{p_{x}}$

where $p_{x}$ is the pitch in the main flow direction (Fig. 1). In Eq. (10), $\tau$ and $K_{0}$ represent the tortuosity coefficient and shape factor, respectively.

Wanniarachchi et al. (1995) proposed the following experimental correlation to predict coefficient $K$ for laminar Newtonian flows in chevron-type PHEs:

$K=1774 / \beta^{1.026}$. 
From the works of Wanniarachchi et al. (1995) and Kumar (1984) it is possible to conclude that in PHE passages the laminar flow ends for Reynolds numbers (critical Reynolds number) located in the range 10-100 and that the critical Reynolds number decreases with the decrease of $\beta$.

PHEs manufacturers (Ayub, 2003) recommend the data (coefficient $K$ ) from Kumar (1984) as a first approximation and the data from Wanniarachchi et al. (1995) (Eq. (12)) for elaborate calculations.

Fernandes et al. (2007) found a good agreement between their numerical data (Eq. (10)) and the data from Wanniarachchi et al. (1995) (Eq. (12)) for common values of $\gamma$ and $\beta$. Therefore, the numerical model used in the present work have shown to be reliable in order to predict the heat transfer to a non-Newtonian fluid $-n=0.42$ - (Fernandes et al., 2005, 2006) and Fanning friction factors of Newtonian fluids (Fernandes et al., 2007), under laminar regime.

The aim of the present work is to study fully developed laminar flows of power-law fluids ( $n=0.25,0.33,0.5,0.67,0.88,0.95$ and 1 ) in chevron-type PHEs passages, containing plates with an area enlargement factor of 1.17, a value commonly used for these type of plate heat exchangers (García-Cascales et al., 2007; Kumar, 1984; Martin, 1996). The different channels had an inter-plates distance of $2.5 \mathrm{~mm}$ and the corrugation angle varied between $31^{\circ}$ and $60^{\circ}\left(31^{\circ}, 35^{\circ}, 40^{\circ}, 45^{\circ}, 50^{\circ}, 55^{\circ}\right.$ and $\left.60^{\circ}\right)$ since $\beta$ is typically located between $22^{\circ}$ and $65^{\circ}$ (Palm and Claesson, 2006; Ayub, 2003; Kakaç and Liu, 2002). The geometrical properties of the studied plates are presented in Table 1, this geometric properties being different from previous ones (Fernandes et al., 2005, 2006; Fernandes et al., 2007). A generalised Reynolds number is developed by extending an empirical methodology (Eq. (9)) from Rene et al. (1991) (found for $\beta=30^{\circ}$ ) to the PHEs studied in the present work, simple $f R e_{\mathrm{g}}=K$ correlations being proposed. In a previous study (Fernandes et al., 2007) with Newtonian fluids it was shown that the tortuosity coefficient plays an important role on the PHEs hydraulic performance. Due to this, the influence of $n$ on $\tau$ is also studied in the present work.

\section{Numerical simulations}

The numerical calculations were performed using the finite-element computational fluid dynamics (CFD) program POLYFLOW ${ }^{\circledR}$. The equations solved were the conservation of mass and momentum equations for laminar incompressible flow of power-law fluids (Eq. (1)).

The simulations were performed using channels containing seven consecutive unitary cells (Ciofalo et al., 1996; Mehrabian and Poulter, 2000; Fernandes et al., 2007), since fully developed flows were achieved in the fifth or sixth consecutive cell, as in past works (Ciofalo et al., 1996; Fernandes et al., 2007).

The unitary cell (Fig. 1) developed by Fernandes et al. (2007) differs from the unitary cell used by Ciofalo et al. (1996) and Mehrabian and Poulter (2000) since it includes five contact points (four in the corners and one in the centre of the cell) instead of four

Table 1

Geometrical properties of the plates

\begin{tabular}{lll}
\hline Name & $\beta\left(^{\circ}\right)$ & $\gamma$ \\
\hline P1 & 31 & 0.474 \\
P2 & 35 & 0.453 \\
P3 & 40 & 0.424 \\
P4 & 45 & 0.391 \\
P5 & 50 & 0.356 \\
P6 & 55 & 0.317 \\
P7 & 60 & 0.277 \\
\hline
\end{tabular}

(all in the corners). Fernandes et al. (2007) established the referred unitary cell after observing the periodicity of the flow during the cooling of stirred yoghurt in half of a chevron-type PHE passage (Fernandes et al., 2005, 2006; Maia et al., 2007). In both approaches, the numerical results compared well with experimental data (Afonso et al., 2003; Wanniarachchi et al., 1995) from the literature; but the former approach (unitary cells) provides lower CPU times.

Due to the complexity of the computational domain, an unstructured mesh constituted by tetrahedral, hexahedral and pyramidal elements was used (Fernandes et al., 2005, 2006; Fernandes et al., 2007).

For each of the channels, the size of the elements was fixed after a grid independence test. The grids were successively refined and the Friction factors obtained with the different meshes were compared, the results being considered independent of the mesh when a difference bellow $1 \%$ was achieved (Fernandes et al., 2007). Table 2 represents an example $\left(\beta=45^{\circ}\right.$ and $\left.n=1\right)$ of this procedure. It can be observed that the deviation between the $f$ values obtained with the mesh constituted by 222,428 elements and the thinner mesh is less then $1 \%$. Thus, the mesh containing 222,428 elements was used in the numerical calculations.

The $f$ values reported in Table 2 were determined in fully developed flow for a Newtonian fluid, the Reynolds number being 4.599. The pressure (obtained using POLYFLOW ${ }^{\circledR}$ ) at the inlet and outlet of each of the seven consecutive unitary cells (Fig. 1) allowed the calculation of the pressure drop in the different cells. Since the values of $u, \rho, D_{\mathrm{H}}$ and $L$ ( $p_{x}$ for a unitary cell) are known, the values of $f$ could be estimated for each cell (Eq. (7)). The values of $f$ reported in Table 2 were that from the fifth or sixth consecutive unitary cell, since an asymptotic result (fully developed flow) was reached in these cells (Ciofalo et al., 1996; Fernandes et al., 2007).

Using the relation from Wanniarachchi et al. (1995) (Eq. (12)) it is possible to estimate $f$. For a Reynolds number of 4.599 and $\beta=45^{\circ}$ it follows that $f=7.7642$. This result compares very well (difference of $2.9 \%$ ) with the one determined numerically (7.5415).

As already referred, the aim of the present work is to study fully developed laminar flows of power-law fluids in chevron-type PHEs passages. Therefore, the pressure drop correlations that will be presented in Section 4 are applicable to the losses in the passages alone and exclude the port pressure drop (Kakaç and Liu, 2002) and the losses related with entry effects. Despite this, these additional pressure drops can be easily estimated. It will be seen that they are very low since the Reynolds numbers under analysis are also low (laminar regime in PHEs).

Plate P4 (see Table 1) represents a plate from a PHE manufacturer. The port to port length and the plate width from plate P4 are $719 \mathrm{~mm}$ and $334 \mathrm{~mm}$, respectively, the port diameter being $100 \mathrm{~mm}$. For $R e=4.599$ and in a PHE passage formed by the referred plates, the value of the pressure drop including entry effects is $0.05 \%$ higher than that obtained in a fully developed flow. Obviously, this increase is dependent on the plate length. The increase would be higher in a plate with a lower length. For instance, for a plate with half of the length (about $350 \mathrm{~mm}$ ) of that from plate P4, that increase would be about $0.1 \%$, but plates with lengths higher than $4 \mathrm{~m}$ (Kakaç and Liu, 2002) can also be found in the industry. For $R e=4.599$, the ratio between the port (with diameter 100

Table 2

Grid independence test

\begin{tabular}{llll}
\hline Nodal distance $(\mathrm{mm})$ & Number of elements & Number of nodes & $f$ \\
\hline 0.4 & 299,527 & 61,991 & 7.49 \\
0.45 & 222,428 & 46,470 & 7.54 \\
0.5 & 171,226 & 36,182 & 7.62 \\
\hline
\end{tabular}


$\mathrm{mm}$ ) pressure drop (Kakaç and Liu, 2002) and the passage pressure drop (including or not including entry effects) is about $3.1 \times 10^{-6}$. If the referred plates had ports with diameter close to $50 \mathrm{~mm}$, the ratio between port pressure drop and passage pressure drop would be close to $5 \times 10^{-5}$.

Detailed information about the boundary conditions used on the present work can be found elsewhere (Fernandes et al., 2007).

\section{Model validation}

When validating a CFD work with literature data it is important to choose models that have been confirmed to be of high quality (Versteeg and Malalasekera, 1995). Since Ayub (2003) recommends the data (coefficient $K$ ) from Kumar (1984) and Wanniarachchi et al. (1995), the numerical results of the present work are compared with the experimental data from the referred works.

In Table 3 the Newtonian numerical results of $K$ obtained in the present work $\left(\beta=31^{\circ}\right.$ and $\left.60^{\circ}\right)$ are compared with the experimental data from Kumar (1984) and Wanniarachchi et al. (1995) (Eq. (12)). For $\beta=60^{\circ}$ the numerical result is located between the data from the two different sources. For $\beta=31^{\circ}$ it was found a good agreement between the numerical result and the data from Wanniarachchi et al. (1995). Kumar (1984) studied a PHE with $\beta=30^{\circ}$ and found $K=50$, this value being close to the numerical value obtained with $\beta=31^{\circ}$. In Table 3 it can also be observed a good agreement between the numerical results and the model (Eq. (14)) proposed by Fernandes et al. (2007).

For the two different values of $\beta$ presented in Table 3 the maximum and average deviation between the numerical data and different data from the literature (Kumar, 1984; Wanniarachchi et al., 1995 ) is $8.47 \%$ and $5.04 \%$, respectively.

CFD investigations can also be validated by performing comparisons with analytical solutions of similar but simpler flows (Versteeg and Malalasekera, 1995). For validation of the numerical method used in the present work, Fernandes et al. (2007) studied the laminar flow of Newtonian fluids trough three different chevron-type PHEs with $\beta=90^{\circ}$ (double-sine ducts). The numerical results of $K$ were close to the analytical solutions from Ding and Manglik (1996) (maximum difference of $0.21 \%$ ).

\section{Results}

For the different plates (see Table 1) and different values of the flow index behaviour, $g(n)$ was determined as suggested by Delplace and Leuliet (1995), i.e., by measuring the numerical values of the pressure drops for imposed flow rates in fully developed flow (in the fifth or sixth consecutive unitary cell), as described in Section 2. Resorting to Eqs. (2)-(4), $g(n)$ was calculated as:

$g(n)=\sqrt[n]{\frac{2^{n-1} f \rho u^{2-n} D_{\mathrm{H}}^{n}}{K^{n} \eta_{0}}}$.

The simulations performed with the Newtonian fluid allowed the values of $K$ to be determined. It was found that the empirical model proposed by Rene et al. (1991) (Eq. (9)) describes well the numerical values of $g(n)$ for the different chevron angle plates (Fig. 2).

Table 3

Values of $K$ for different plates

\begin{tabular}{lllcl}
\hline$\beta$ & Numerical & $\begin{array}{l}\text { Fernandes et al. } \\
(2007)\end{array}$ & $\begin{array}{l}\text { Kumar } \\
(1984)\end{array}$ & $\begin{array}{l}\text { Wanniarachchi et al. } \\
(1995)\end{array}$ \\
\hline 31 & 53.78 & 52.49 & - & 52.34 \\
60 & 24.33 & 25.06 & 24.00 & 26.58 \\
\hline
\end{tabular}

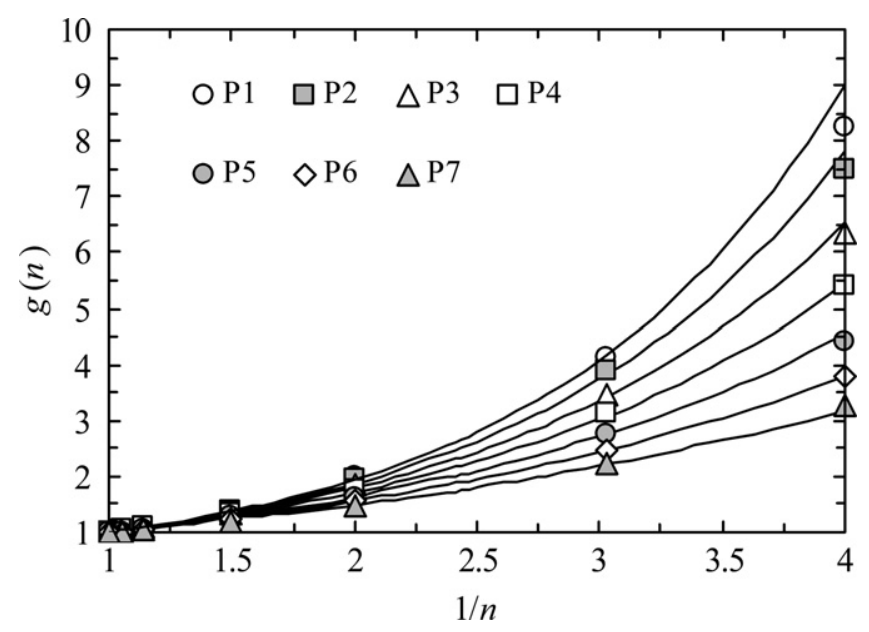

Fig. 2. Function $g(n)$ for distinct plates. Lines represent Eq. (9) with $\alpha$ given by Eq. (14).

Plate P1 $\left(\beta=31^{\circ}\right)$ gave rise to a value of $\alpha \cong 0.27$ while for plate P7 $\left(\beta=60^{\circ}\right)$ the value of $\alpha$ was close to 0.08 . The value of $\alpha$ found with plate P1 compares well with the experimental value (0.3) reported by Rene et al. (1991) for a plate (V13) with corrugation angle $30^{\circ}$. It is important to note that both plates (V13 and P1) are from the chevron-type and that Rene et al. (1991) used values of $n$ (between 0.26 and 1 ) covered by the range studied in the present work.

For the different values of $\beta$ (see Table 1 ), the geometrical parameter $\alpha$ can be predicted $\left(R^{2}=0.998\right)$ by:

$\alpha=0.4731-0.0065 \beta$.

For a given PHE passage, numerical and experimental approaches may give rise to different pressure drop values, obtained for a certain power-law fluid and operating conditions. Using Eqs. (13), (9), and (7) the ratio between experimental, $\Delta P_{\exp }$, and numerical, $\Delta P_{\text {num }}$, pressure drop is given by:

$\frac{\Delta P_{\exp }}{\Delta P_{\text {num }}}=\left(\frac{K_{\text {exp }}}{K_{\text {num }}}\right)^{n} n^{\alpha_{\text {num }}-\alpha_{\text {exp }}}$

As mentioned above, for a V13 plate (Rene et al., 1991), $\alpha_{\text {exp }}=0.3$. The chevron-type V13 plates $\left(\gamma=0.5512\right.$ and $\left.\beta=30^{\circ}\right)$ from Société VICARB (Leuliet et al., 1990; Rene et al., 1991) were used by this group in many experimental studies (Rene et al., 1991; Leuliet et al., 1989, 1990, 1993; Leuliet and Maigonnat,1992), $K_{\exp }$ being equal to 58.84 (Rene et al., 1991). The value $K_{\text {num }}=55.88$ can be estimated using Eq. (10) (obtained through numerical calculations) and the referred values of $\gamma$ and $\beta$. For $\beta=30^{\circ}$ Eq. (14) predicts $\alpha_{\text {num }}=0.2781$, it being assumed that this value applies to a passage formed by V13 plates.

In the work from Rene et al. (1991) $n$ varied between 0.26 and 1, the experimental value $\alpha_{\exp }=0.3$ being obtained using aqueous solutions of guar-gum, carboxymethylcellulose, sucrose and water. For a V13 PHE passage, the ratio (Eq. (15)) between the experimental pressure drop (Rene et al., 1991) and numerical pressure drop (estimated in the present work) reaches a maximum of 1.0529 for $n=1$ when the value $\alpha_{\text {num }}=0.2781$ is used. Using $\alpha_{\text {num }}=0.2716$ $\left(\beta=31^{\circ}\right.$ in Eq. (14)) the referred ratio reaches a maximum of 1.0530 for $n=0.26$.

The PHE used by Rene et al. (1991) had a series arrangement and the V13 plates had width, length and port diameters of $204 \mathrm{~mm}, 636 \mathrm{~mm}$ and around $60 \mathrm{~mm}$, respectively, and the interplates distance being $3.5 \mathrm{~mm}$ (Rene et al., 1991; Leuliet et al., 1990). As already shown (see Section 2), for plates with these 
dimensions and in laminar regime, port pressure drop and pressure drop related with entry effects are negligible.

In Fig. 2 it is possible to observe that the relation between $g(n)$ and $1 / n$ is not of the linear type (Eq. (8)) in the entire range of $n$. Manglik and Ding (1997) studied the flow of power-law fluids in chevron-type PHEs with $\beta=90^{\circ}$ (double-sine ducts) and concluded that due to the presence of sharp corners, the methodology developed by Kozicki et al. (1966) provided a reasonable agreement with their numerical data in a moderate region of $n$ $(0.6 \leqslant n \leqslant 1.5)$. It was not unexpected that the same could happen with the geometries studied in the present work since they also include sharp corners (planes A, C and E in Fig. 3). In addition, the present geometries have severe contractions and expansions, the flow being tortuous (Fernandes et al., 2007). This is a major difference between the flows studied by Kozicki et al. (1966) and the present ones.

By including Eq. (14) in Eq. (9) it was possible to establish a single friction curve (Eq. (3)) for each of the seven corrugation angles, for both Newtonian and non-Newtonian fluids (Fig. 4). For the sake of clarity of Fig. 4 , the results with $n=0.33,0.67,0.88$ and 0.95 are not included.

For each $\beta$, the average value of $K$ was calculated (Table 4 ). This average was determined using the results of $K$ obtained for the different values of $n(0.25,0.33,0.5,0.67,0.88,0.95$ and 1$)$. It may be seen that for each corrugation angle the standard deviation is very low.

Eq. (10) (obtained using numerical data) or Eq. (12) (a experimental relation) can be used in order to find the proper value of $K$ for each single friction curve but Eq. (10) describes better the present results of $K$, obtained with the distinct values of $n$ (maximum and average difference of $5 \%$ and $1.9 \%$, respectively), when compared with Eq. (12) (maximum and average difference of 9\%

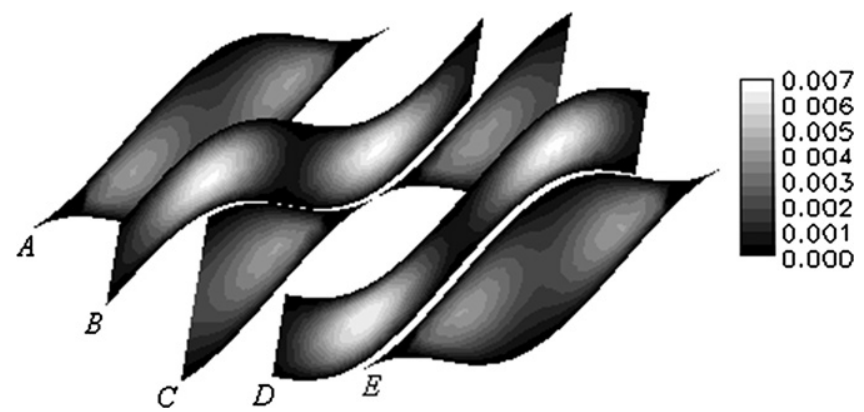

Fig. 3. Velocity distribution in $x$ plans for plate $\mathrm{P} 1$ and $u=1.64 \times 10^{-3} \mathrm{~ms}^{-1}$.

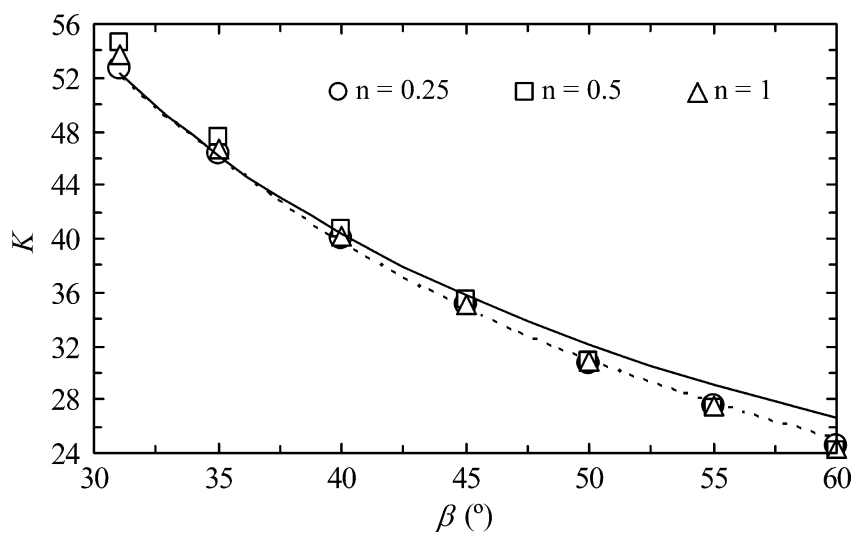

Fig. 4. Constant $K$ for different values of flow index behaviour. (---) Eq. (10) and (-) Eq. (12). and $3.5 \%$, respectively). The difference of $9 \%$ was found for $\beta=60^{\circ}$ (Fig. 4). As already shown (Table 3), for this angle the pres-

Table 4

Average values of $K$ and standard deviation

\begin{tabular}{lll}
\hline$\beta\left({ }^{\circ}\right)$ & K-average value & Standard deviation \\
\hline 31 & 53.99 & 0.73 \\
35 & 46.99 & 0.44 \\
40 & 40.35 & 0.26 \\
45 & 35.28 & 0.13 \\
50 & 30.78 & 0.07 \\
55 & 27.43 & 0.03 \\
60 & 24.31 & 0.11 \\
\hline
\end{tabular}
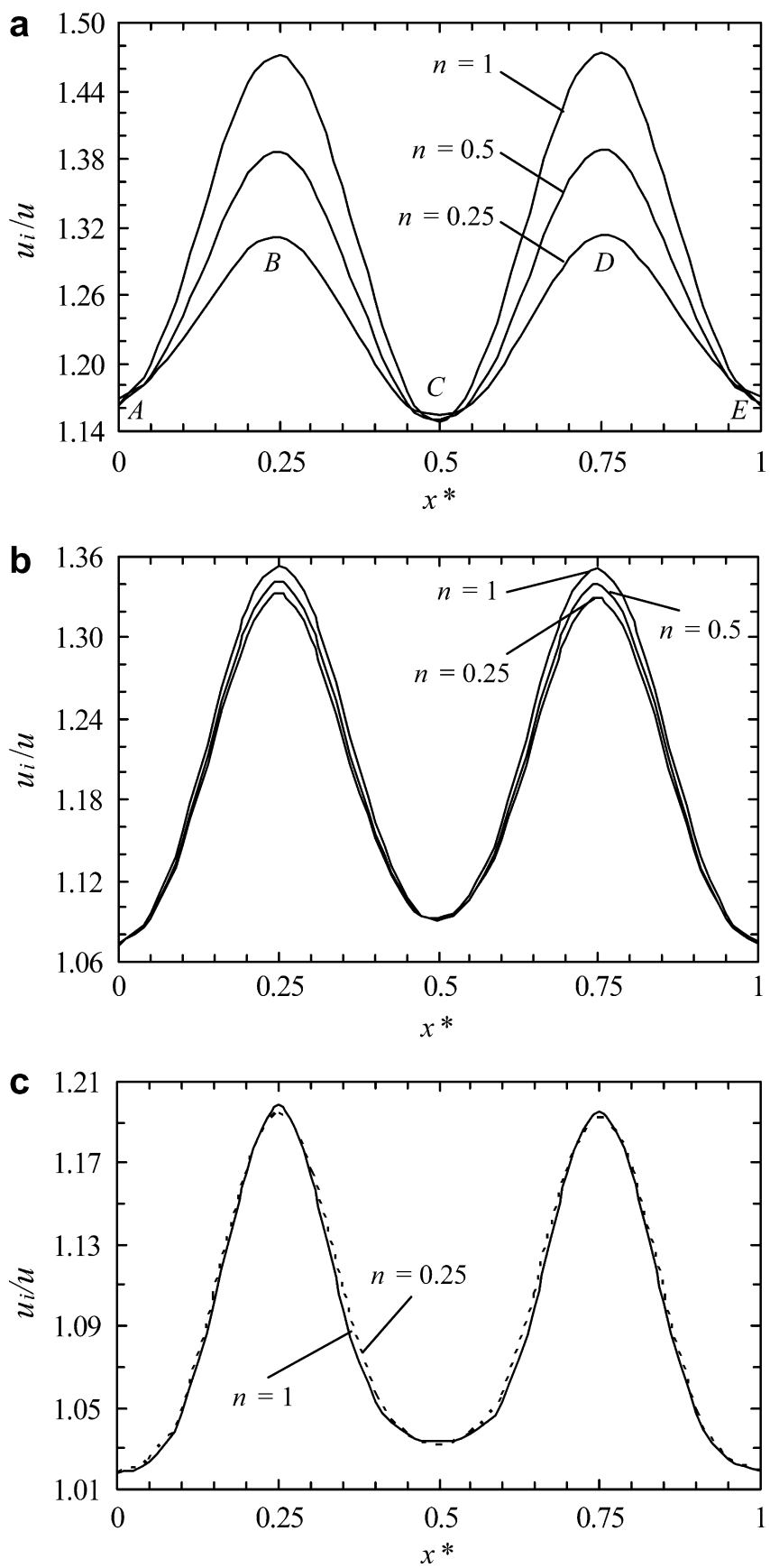

Fig. 5. Ratio $u_{i} / u$ for distinct values of flow index behaviour and different plates. (a) P1, (b) P4 and (c) P7. 
ent $K$ numerical results (and Eq. (10)) are in better agreement with the experimental value, $K=24$, from Kumar (1984).

The behaviour of local interstitial velocities, $u_{i}$, in fully developed flow (in the fifth or sixth consecutive unitary cell) were analysed - in the main flow direction - for the different values of corrugation angle and flow index behaviour (Fig. 5). In order to do it, it was defined a normalized length $x^{*}=\left(x / p_{x}-\right.$ cell number -1$), x^{*}$ being equal to zero and one at the inlet and outlet of the studied unitary cell (cell number $=5$ or 6 ), respectively. In Fig. 5 it is possible to detect the tortuous character of the flow in PHEs passages (Fernandes et al., 2007) since the local interstitial velocity is higher than the average velocity $u$.

For all values of $\beta$, the interstitial velocity shows the lowest values at the inlet $\left(x^{*}=0\right)$, plane including the contact point in the centre of the unitary cell $\left(x^{*}=0.5\right)$ and outlet $\left(x^{*}=1\right)$, i.e., plans $\mathrm{A}$, $\mathrm{C}$ and $\mathrm{E}$ in Fig. $3\left(\beta=31^{\circ}\right)$, since these plans present large cross-sectional areas. The maximum values of $u_{i}$ are reached - for all values of $\beta$ - at $x^{*}=0.25$ and 0.75 , i.e., plans $B$ and $D$ in Fig. $3\left(\beta=31^{\circ}\right)$. In Fig. 5 it is also possible to observe that for each corrugation angle the local interstitial velocities increase with increasing $n$. This effect is attenuated with the increase of $\beta$ ( Fig. $5 a-c$ ) and for $\beta=60^{\circ}$ the $u_{i}$ curves - for the different values of $n$ - are essentially overlapped (Fig. 5c).

The study of local interstitial velocities allows the tortuosity coefficient defined (Fernandes et al., 2007) by the ratio between the average interstitial velocity and $u$, to be estimated. The tortuos-

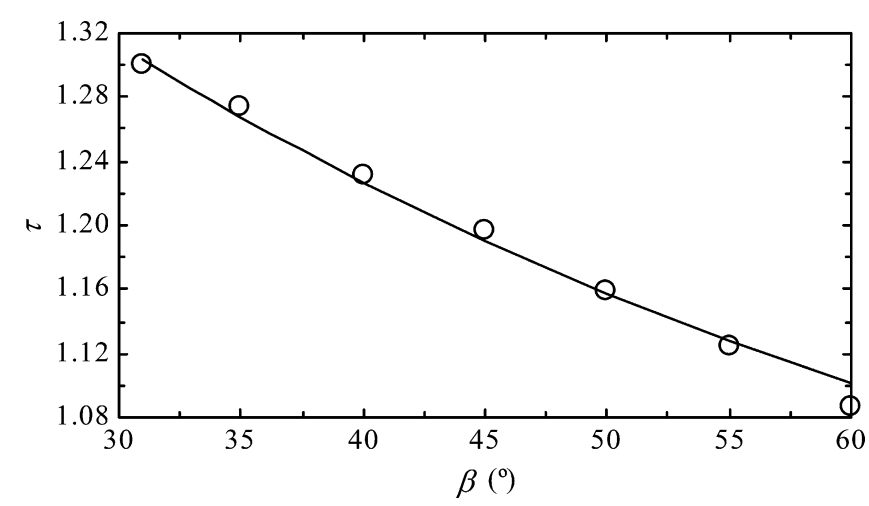

Fig. 6. Tortuosity coefficient for $n=1$. (O) Numerical values and (-) model from Fernandes et al. (2007).

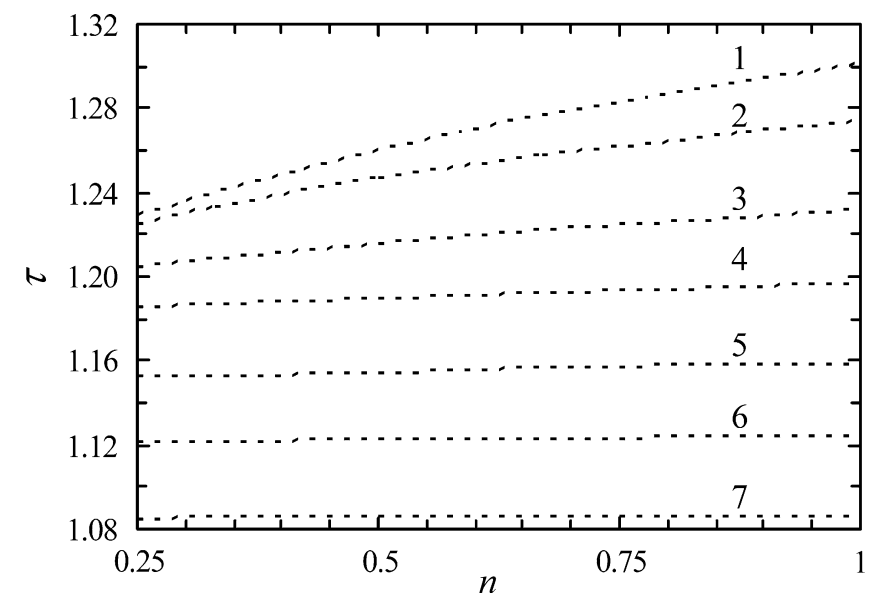

Fig. 7. Tortuosity coefficient in different channels. (1) P1, (2) P2, (3) P3, (4) P4, (5) P5, (6) P6 and (7) P7. ity coefficients are used by PHEs manufactures (Charre et al., 2002) to estimate friction factors and convective heat transfer coefficients.

For $n=1$, the values of $\tau$ are well described by the model from Fernandes et al. (2007) (Fig. 6). As expected (Fig. 5), the values of the tortuosity coefficient decrease with the decrease of $n$ (Fig. 7), this variation being more pronounced for low corrugation angles. This dependence between $\tau$ and $n$ was also found by Balhoff and Thompson (2006) in studies devoted to the flow of power-law fluids through granular beds.

Friction factors of shear-thinning fluids are lower than those from Newtonian fluids. The tortuosity coefficient is included in the proposed single friction curves for both Newtonian and nonNewtonian fluids (Eqs. (3) and (10)), this tortuosity coefficient being that from the Newtonian flows (Fig. 6). Hence, the variation of this coefficient with $n$ is also (besides the shear-thinning effect) incorporated in the developed generalised Reynolds number.

\section{Conclusions}

Using CFD techniques it was possible to propose single friction curves for the fully developed laminar flow of Newtonian and various shear-thinning fluids through cross-corrugated chevron-type PHEs. The PHEs had different corrugation angles and the area enlargement assumed a value commonly used in the industry.

Due to the geometrical complexity of the cross-corrugated chevron-type PHEs passages, the velocity profiles and, therefore, the shear rate behaviour are also complex. Hence, it is difficult to predict the apparent viscosity observed during the flow of shearthinning fluids in this type of equipments and, consequently, the fRe correlations including this viscosity are of limited utility. This limitation can be solved by using a generalised viscosity. The latter approach was used in the current investigation, the proposed $f R e_{\mathrm{g}}$ correlations being most useful to the practical area.

It was shown that the flow index behaviour influences the velocity profiles and the magnitude of the average interstitial velocity. As a result of this effect, for each corrugation angle, the tortuosity coefficient decreases with the decrease of the referred index.

\section{References}

Afonso, I.M., Hes, L., Maia, J.M., Melo, L.F., 2003. Heat transfer and rheology of stirred yoghurt during cooling in plate heat exchangers. Journal of Food Engineering 57, 179-187.

Ayub, Z.H., 2003. Plate heat exchanger survey and new heat transfer and pressure drop correlations for refrigerant evaporators. Heat Transfer Engineering 24, 3 16.

Balhoff, M.T., Thompson, K.E., 2006. A macroscopic model for shear thinning flow in packed beds based on network modelling. Chemical Engineering Science 61, 698-719.

Broniarz-Press, L., Agacinski, P., Rozanski, J., 2007. Shear-thinning fluids flow in fixed and fluidised beds. International Journal of Multiphase Flow 33, 675-689.

Carezzato, A., Alcantara, M.A., Telis-Romero, J., Tadini, C.C., Gut, J.A., 2007. NonNewtonian heat transfer on a plate heat exchanger with generalized configurations. Chemical Engineering Technology 30, 21-26.

Charre, O., Jurkowski, R., Bailly, A., Meziani, S., Altazin, M., 2002. General model for plate heat exchanger performance prediction. Journal of Enhanced Heat Transfer 9, 181-186.

Chhabra, R.P., Comiti, J., Machač, I., 2001. Flow of non-Newtonian fluids in fixed and fluidised beds. Chemical Engineering Science 56, 1-27.

Ciofalo, M., Stasiek, J., Collins, M.W., 1996. Investigation of flow and heat transfer in corrugated passages - II. Numerical simulation. International Journal of Heat and Mass Transfer 39, 165-192.

Delplace, F., Leuliet, J.C., 1995. Generalized Reynolds number for the flow of power law fluids in cylindrical ducts of arbitrary cross-section. The Chemical Engineering Journal 56, 33-37.

Dias, R., Teixeira, J.A., Mota, M., Yelshin, A., 2006. Tortuosity variation in a low density binary particulate bed. Separation and Purification Technology 51, 180 184.

Dias, R.P., Fernandes, C.S., Mota, M., Teixeira, J.A., Yelshin, A., 2007. Permeability and effective thermal conductivity of bisized porous media. International Journal of Heat and Mass Transfer 50, 1295-1301. 
Dias, R.P., Fernandes, C.S., Teixeira, J.A., Mota, M., Yelshin, A., 2008. Permeability analysis in bisized porous media: wall effect between particles of different size. Journal of Hydrology 349, 470-474.

Ding, J., Manglik, R.M., 1996. Analytical solutions for laminar fully developed flows in double-sine shaped ducts. Heat and Mass Transfer 31, 269-277.

Edwards, M.F., Vaie, A.A.C., Parrott, D.L., 1974. Heat transfer and pressure drop characteristics of a plate heat exchanger using Newtonian and non-Newtonian liquids. The Chemical Engineer 293, 286-288.

Fernandes, C.S., Dias, R., Nóbrega, J.M., Afonso, I.M., Melo, L.F., Maia, J.M., 2005. Simulation of stirred yoghurt processing in plate heat exchangers. Journal of Food Engineering 69, 281-290.

Fernandes, C.S., Dias, R.P., Nóbrega, J.M., Afonso, I.M., Melo, L.F., Maia, J.M., 2006 Thermal behaviour of stirred yoghurt during cooling in plate heat exchangers. Journal of Food Engineering 76, 433-439.

Fernandes, C.S., Dias, R.P., Nóbrega, Maia, J.M., 2007. Laminar flow in chevron-type plate heat exchangers: CFD analysis of tortuosity, shape factor and friction factor. Chemical Engineering and Processing: Process Intensification 46, 825833.

García-Cascales, J.R., Vera-García, F., Corberán-Salvador, J.M., Gonzálves-Maciá, J. 2007. Assessment of boiling and condensation heat transfer correlations in the modelling of plate heat exchangers. International Journal of Refrigeration 30, 1029-1041.

Gut, J.A.W., Pinto, J.M., 2003. Modeling of plate heat exchangers with generalized configurations. International Journal of Heat and Mass Transfer 46, 25712585.

Kakaç, S., Liu, H., 2002. Heat Exchangers Selection, Rating, and Thermal Design, second ed. CRC Press, Boca Raton. pp. 131-136, 373-412.

Kim, B.K., Tadini, C.C., Singh, R.K., 1999. Heat transfer in a plate heat exchanger during pasteurization of orange juice. Journal of Food Engineering 42, 79-84.

Kozicki, W., Chou, C.H., Tiu, C., 1966. Non-Newtonian flow in ducts of arbitrary cross-sectional shape. Chemical Engineering Science 21, 665-679.

Kumar,H., 1984. The plate heat exchanger: construction and design. In: Proceedings First UK National Conference on Heat Transfer, University of Leeds, Inst. Chem. Symp. Series No. 86, pp. 1275-1288.

Leuliet J.C., Devienne, R., Naimi, M., Maigonnat, J.F., Lalande, M., Lebouche, M., 1989 Incidence du seil d'ecoulement sur les performances thermohydrauliques des echangeurs. In: Proceedings 2ème Colloque TIFAN, La Baule.

Leuliet, J.C., Maigonnat, J.F., 1992. Influence du seil d'ecoulement sur les performances thermiques d'echangeurs de caleur à plaques. In: Proceedings 5ème Colloque TIFAN, Strasbourg, France, pp. 1-14

Leuliet, J.C., Maigonnat, J.F., Lalande, M., 1987. Etude de la perte de charge dans de échangeurs de chaleur à plaques traitant des produits non-newtoniens. Revue Générale de Thermique, 445-450.
Leuliet, J.C., Maigonnat, J.F., Lalande, M., 1990. Écoulements et transferts de chaleur dans les échangeurs à plaques traitant des produits visqueux Newtoniens et Pseudoplastiques. The Canadian Journal of Chemical Engineering 68, 220-229.

Leuliet, J.C., Maigonnat, J.F., Lalande, M., 1988. Thermal behaviour of plate heat exchangers with Newtonian and non-Newtonian fluids. In: Proceedings Congress Eurotherm 5 et Colloque TIFAN, Compiègne, pp. 1-15.

Leuliet, J.C., Delplace, F., Maigonnat, J.F., 1993. Performences thermiques d'echangeurs de chaleur traintant des fluides à seuil. In: Proceedings Gème Colloque TIFAN, Le CROISIC.

Maia, J.M., Nóbrega, J.M., Fernandes, C.S., Dias, R.P., 2007. CFD simulation of stirred yoghurt processing in plate heat exchangers. In: Sun, Da-Wen (Ed.), Computational Fluid Dynamics in Food Processing. CRC Press, pp. 381-402. (Chapter 15).

Manglik, R.M., Ding, J., 1997. Laminar flow heat transfer to viscous power-law fluids in double-sine ducts. International Journal of Heat and Mass Transfer 40, 13791390.

Martin, H., 1996. A theoretical approach to predict the performance of chevron-type plate heat exchangers. Chemical Engineering and Processing 35, 301-310.

Mehrabian, M.A., Poulter, R., 2000. Hydrodynamics and thermal characteristics of corrugated channels: computational approach. Applied Mathematical Modelling 24, 343-364.

Metwally, H.M., Manglik, R.M., 2000. A computational study of enhanced laminar flow heat transfer in laminar flows of non-Newtonian fluids in corrugated-plate channels. In: Proceedings ASME Advances in Enhanced Heat Transfer, HTD-vol. 365/PID-vol. 4, pp. 41-48.

Metwally, H.M., Manglik, R.M., 2002. Computational modelling of enhanced laminar flow heat transfer in viscoplastic fluids in corrugated-plate channels. In: Proceedings ASME International Mechanical Engineering Congress \& Exposition, New Orleans, Louisiana, pp. 1-8.

Metzner, A.B., Reed, J.C., 1955. Flow of non-Newtonian fluids - correlation of the laminar, transition, and turbulent-flow regions. AICHE Journal 1, 434-440.

Palm, B., Claesson, J., 2006. Plate heat exchangers: calculation methods for singleand two-phase flow. Heat Transfer Engineering 27, 88-89.

Rene, F., Leuliet, J.C., Lalande, M., 1991. Heat transfer to Newtonian and nonNewtonian food fluids in plate heat exchangers: experimental and numerical approaches. Trans IChemE 69, 115-126.

Steffe, J.F., 1996. Rheological Methods in Food Process Engineering, second ed. Freeman Press, East Lansing. pp. 366-370.

Versteeg, H.K., Malalasekera, W., 1995. An Introduction to Computational Fluid Dynamics. Pearson Prentice Hall, Harlow. pp. 8.

Wanniarachchi, A.S., Ratnam, U., Tilton, B.E., Dutta-Roy, K., 1995. Approximate correlations for chevron-type plate heat exchangers. In: Proceedings ASME HTDvol. 314, 1995 National Heat Transfer Conference, vol. 12, pp. 145-151. 